\title{
MRI imaging features of HIV-related central nervous system diseases: diagnosis by pattern recognition in daily practice
}

\author{
Mio Sakai ${ }^{1}$ ( Masahiro Higashi ${ }^{2} \cdot$ Takuya Fujiwara $^{2} \cdot$ Tomoko Uehira $^{3} \cdot$ Takuma Shirasaka $^{3} \cdot$ Katsuyuki Nakanishi $^{1}$. \\ Nobuo Kashiwagi ${ }^{4} \cdot$ Hisashi Tanaka $^{5} \cdot$ Hitoshi Terada $^{6} \cdot$ Noriyuki Tomiyama $^{5}$
}

Received: 4 April 2021 / Accepted: 1 June 2021 / Published online: 14 June 2021

(c) The Author(s) 2021

\begin{abstract}
With the advent of antiretroviral therapy (ART), the prognosis of people infected with human immunodeficiency virus (HIV) has improved, and the frequency of HIV-related central nervous system (CNS) diseases has decreased. Nevertheless, mortality from HIV-related CNS diseases, including those associated with ART (e.g., immune reconstitution inflammatory syndrome) remains significant. Magnetic resonance imaging (MRI) can improve the outlook for people with HIV through early diagnosis and prompt treatment. For example, HIV encephalopathy shows a diffuse bilateral pattern, whereas progressive multifocal leukoencephalopathy, HIV-related primary CNS lymphoma, and CNS toxoplasmosis show focal patterns on MRI. Among the other diseases caused by opportunistic infections, CNS cryptococcosis and CNS tuberculosis have extremely poor prognoses unless diagnosed early. Immune reconstitution inflammatory syndrome shows distinct MRI findings from the offending opportunistic infections. Although distinguishing between HIV-related CNS diseases based on imaging alone is difficult, in this review, we discuss how pattern recognition approaches can contribute to their early differentiation.
\end{abstract}

Keywords HIV · HIV-related central nervous system diseases · AIDS · MRI · Antiretroviral therapy

\section{Introduction}

Mio Sakai

s-mio@umin.ac.jp

1 Department of Diagnostic and Interventional Radiology, Osaka International Cancer Institute, 3-1-69, Otemae, Chuo-ku, Osaka-shi, Osaka 541-8567, Japan

2 Department of Radiology, National Hospital Organization Osaka National Hospital, 2-1-14, Hoenzaka, Chuo-ku, Osaka-shi, Osaka 540-0006, Japan

3 AIDS Medical Center, National Hospital Organization Osaka National Hospital, 2-1-14, Hoenzaka, Chuo-ku, Osaka-shi, Osaka 540-0006, Japan

4 Department of Future Diagnostic Radiology, Osaka University Graduate School of Medicine, 2-2, Yamadaoka, Suita, Osaka 565-0871, Japan

5 Department of Radiology, Osaka University Graduate School of Medicine, 2-2, Yamadaoka, Suita, Osaka 565-0871, Japan

6 Department of Radiology, Toho University Sakura Medical Center, 564-1, Shimoshizu, Sakura, Chiba 285-8741, Japan
In the early 1980, a positive diagnosis of the human immunodeficiency virus (HIV) inevitably led to acquired immunodeficiency syndrome (AIDS) and premature death. HIV causes cellular immunodeficiency primarily by infecting and killing CD4-positive T lymphocytes. The normal absolute serum count for CD4-positive T lymphocytes in adolescents and adults ranges from 500 to 1500 cells $/ \mathrm{mm}^{3}$. In general, the cell count progressively decreases with the increasing duration of HIV infection. At cell counts $<200$ cells $/ \mathrm{mm}^{3}$, patients are severely immunocompromised and classified as having AIDS [1]. Patients may develop opportunistic infections (OIs) or other HIV-related disorders that can lead to death within a few months without appropriate therapy [1].

Since the introduction of antiretroviral therapy (ART), there has been a significant improvement in the prognosis of HIV-infected patients. ART can reduce or entirely prevent immunosuppression and even improve immune status by suppressing HIV growth [2]. ART transforms HIV infection into a manageable chronic condition, potentially allowing patients to have an almost average life expectancy [3]. However, although ART has notably reduced the prevalence 
of HIV-related central nervous system (CNS) diseases, secondary to OIs [4, 5], the associated mortality remains high [4]. Therefore, HIV-related CNS diseases are a major cause of death in patients with HIV [6].

Furthermore, nearly $20 \%$ of HIV-infected people worldwide are reportedly not diagnosed and treated with ART [7]. Thus, it is not unusual for incidental magnetic resonance imaging (MRI) findings to lead to the suspicion of HIVrelated CNS diseases and the subsequent diagnosis of HIV infection [9]. In addition, HIV-infected individuals, who do not adhere to treatment may again become immunodeficient after a few months [8], thus increasing the risk of HIV-related CNS diseases.

MRI, which is minimally invasive and highly reproducible, is one of the most powerful tools for diagnosing and monitoring HIV-related CNS diseases. This article, reviews MRI as a diagnostic tool, focusing on pattern recognition approaches to diagnose HIV-related CNS diseases.

\section{Clinical and laboratory findings of HIV-related CNS diseases}

Information of use in estimating the risk of HIV-related CNS diseases is the serum CD4-positive T lymphocyte count. In patients with counts of $<200$ cells $/ \mathrm{mm}^{3}$, there is a higher risk of HIV encephalopathy, OIs, and primary CNS lymphoma (PCNSL) (Table 1) [10]. Antibody assays of blood serum or

Table 1 Correlation between serum CD4-positive $\mathrm{T}$ lymphocyte counts and risk of HIV-related CNS diseases $[1,10]$

\begin{tabular}{ll}
\hline $\begin{array}{l}\mathrm{CD} 4 \text { count (cell/ } \\
\mathrm{mm}^{3} \text { ) }\end{array}$ & Frequently occurring CNS diseases \\
\hline$>500$ & $\begin{array}{l}\text { Same as in immunocompetent hosts } \\
200-500\end{array}$ \\
$\begin{array}{l}\text { HIV-associated neurocognitive disorders (HAND) } \\
\text { Toxoplasmosis, HIV encephalopathy, Cryptococ- } \\
\text { cosis, PML, PCNSL }\end{array}$ \\
\hline
\end{tabular}

$H I V$ human immunodeficiency virus, $P C N S L$ primary central nervous system lymphoma, $P M L$ progressive multifocal leukoencephalopathy cerebrospinal fluid (CSF), polymerase chain reaction assays of CSF, and CSF or blood cultures are recommended for diagnosing some CNS diseases. Some cases may require a biopsy for confirmation and/or empirical treatment $[11,12]$.

\section{Classification with MRI pattern recognition}

HIV-related CNS diseases can be classified into three groups based on their etiology (1) impairment directly caused by HIV-related neurologic diseases HIV encephalopathy and HIV vasculopathy, (2) OIs, secondary to HIV CNS toxoplasmosis (CNS-Toxo), progressive multifocal leukoencephalopathy (PML), CNS cryptococcosis (CNS-Crypt), CNS tuberculosis (CNS-TB), PCNSL, and (3) ART-related conditions: immune reconstitution inflammatory syndrome (IRIS) and brain damage caused by ART $[1,13,14]$. Furthermore, they can be classified according to the patterns observed on MRI (Table 2) (1) diffuse and bilateral, (2) focal, and (3) meningitis/meningoencephalitis. HIV encephalopathy shows a diffuse bilateral pattern, whereas PML, HIV-related PCNSL, and CNS-Toxo show focal patterns. However, sometimes, a single disease may have multiple imaging features. For example, CNS-TB and CNS-Crypt, which show meningitis/ meningoencephalitis, can present as focal lesions and meningitis. In addition, in some cases, no abnormality is detected on imaging, but such an absence might be an important finding in making a diagnosis. Here, we review MRI findings of HIV-related CNS diseases employing pattern recognition, along with a few exceptions mentioned earlier.

\section{Diffuse and bilateral lesions}

\section{HIV encephalopathy}

\section{Epidemiology and clinical manifestations}

HIV encephalopathy is a neurocognitive disorder primarily caused by HIV. HIV enters the CNS within the first few
Table 2 The most common HIV-related CNS diseases classified by the MRI patterns

\begin{tabular}{ll}
\hline MRI pattern & CNS disease \\
\hline Diffuse and bilateral & HIV encephalopathy \\
Focal brain lesions & CNS Toxoplasmosis (CNS-Toxo) \\
& Primary central nervous system lymphoma (PCNSL) \\
& Progressive multifocal leukoencephalopathy (PML) \\
Meningitis/meningoencephalitis & CNS-Cryptococcosis (CNS-Crypt) \\
& CNS-Tuberculosis (CNS-TB) \\
Others & Immune reconstitution inflammatory syndrome (IRIS) \\
& HIV-related cerebral infarction \\
\hline
\end{tabular}

CNS central nervous system, HIV human immunodeficiency virus, MRI magnetic resonance imaging 
weeks post-infection and causes chronic inflammation [15]. Even on starting ART, many anti-HIV drugs do not cross the blood-brain barrier, and HIV in the brain continues to replicate $[2,3,16]$. In early stages of infection, patients manifest no cognitive symptoms. In later stages, when patients have severe immunodeficiency and manifest cognitive symptoms, pathological findings show HIV leukoencephalopathy characterized by diffuse myelin and axonal degeneration [4]. Since, in many cases, the symptoms improve with ART [3, 4], it is essential to recognize and diagnose the disease at the earliest.

Approximately half of the HIV-infected individuals develop cognitive impairment [15]. Although HIV encephalopathy remains a major cause of cognitive impairment, several comorbidities, such as alcohol and substance abuse; nutritional and vitamin deficiencies, ischemic changes caused by accelerated atherosclerosis due to HIV and ART, and psychiatric illnesses, may also contribute to its development [3]. OIs and PCNSLs may also affect cognition [3]. It has been suggested that chronic inflammation caused by HIV may accelerate age-related changes, and ART may contribute to the deposition of amyloid- $\beta$, a hallmark of Alzheimer's disease, although this theory remains controversial [17]. HIV-associated neurocognitive disorders (HANDs), which correspond to HIV encephalopathy, is a term that has been proposed for medium to long-term cognitive impairment in HIV-infected individuals [18]. It is seen in patients with serum CD4-positive T lymphocyte count between 200 and $500 / \mathrm{mm}^{3}[1,10,12]$ (Table 1). The prevalence of HANDs among HIV-infected individuals has been reported to be around 25\% [19-23]; the common risk factors are low serum CD4-positive $\mathrm{T}$ lymphocytes at the baseline, age of $\geq 50$ years, transient increase in viral load, or virological failure $[17,20,21,24,25]$.

\section{Magnetic resonance findings (Fig. 1)}

The diagnosis and evaluation of HIV encephalopathy commonly require neuropsychological testing but not MRI [18, 20,26]. However, MRI is essential to rule out other causes of cognitive impairment. Conventional MRI often shows no abnormalities, such as mass effects or enhancement, especially in the early stages of the disease. Therefore, if either of these findings is present, other diagnoses should be considered. HIV encephalopathy may be visible on T2-weighted and fluid-attenuated inversion recovery (FLAIR) images, where an increased signal may be seen in the bilateral deep white matter, and rarely, within the subcortical structures or the brain stem (Fig. 1a, b). On T1-weighted images, the lesion shows an iso to slightly low signal (Fig. 1c), this finding is usually apparent in the advanced stages of the disease and is often followed by progressive central-dominant brain atrophy (Fig. 1) [27].

The signal changes in HIV encephalopathy may improve with ART, which may differentiate it from age-related and ischemic changes, however, conventional MRI is not recommended for assessing treatment effectiveness as the symptoms of HIV encephalopathy are not consistently depicted on conventional MRI.

Instead, advanced neuroimaging modalities, such as MR spectroscopy (MRS) [17], diffusion tensor imaging [17, 28], and arterial spin labeling [29] reportedly can be used for evaluating HIV encephalopathy, particularly for monitoring early changes and therapeutic response.

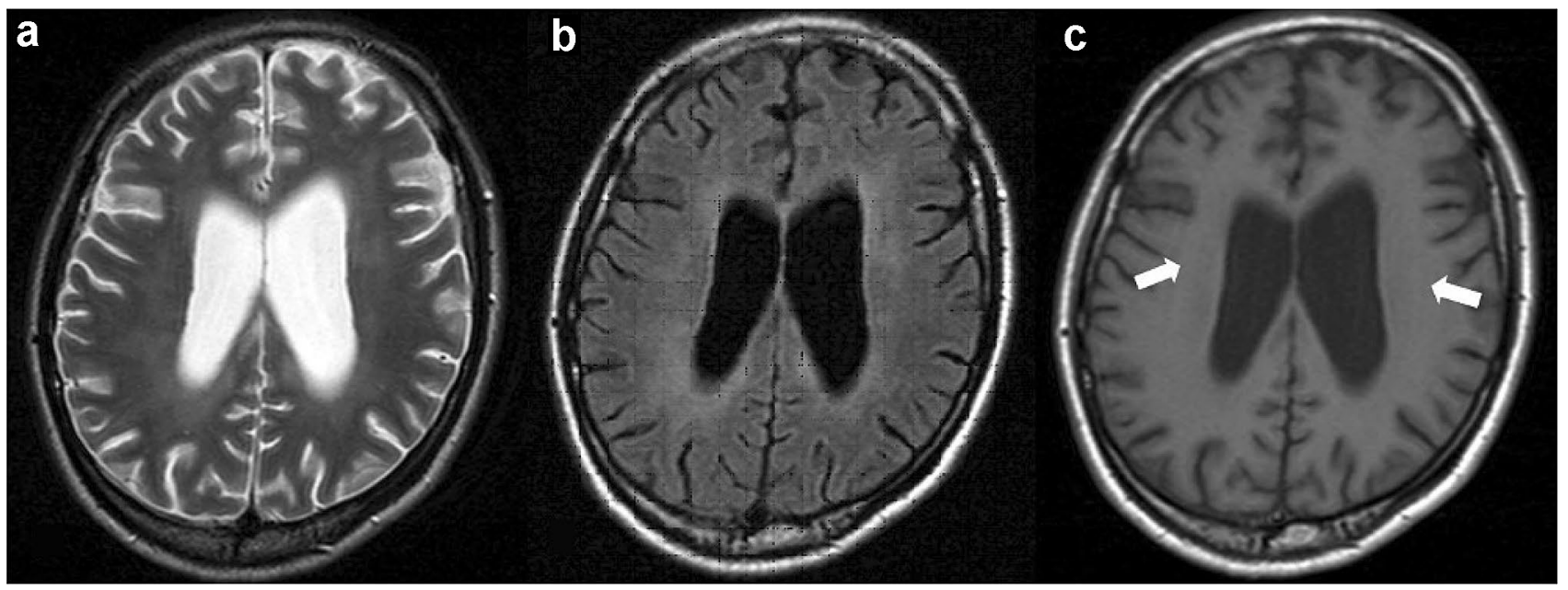

Fig. 1 HIV encephalopathy in a 35-year-old man with HIV infection and memory loss. Brain MRI was performed a few days before the initiation of antiretroviral therapy and showed cerebral atrophy.
T2-weighted (a) and FLAIR images (b) showed a pale hyperintense area in the periventricular white matter. The lesion shows an iso to slightly low signal intensity on T1-weighted image (c, white arrows) 


\section{Focal brain lesions}

Among HIV-related CNS diseases, the focal lesions are most commonly found in patients with CNS-Toxo, PCNSL, and PML [30]. PML is a demyelinating disease caused by human polyomavirus 2 (commonly known as the JC virus) infection, and imaging reveals no mass lesions or enhancement. CNS-Toxo and PCNSL may form similar ringenhanced mass lesions, making the two disorders difficult to differentiate. Since the prognoses of these entities are poor, and they are fatal if left untreated, timely diagnosis is crucial, and appropriate treatment can improve long-term survival [31].

Using other technologies as adjuncts to MRI, such as thallium-201 single-photon emission computed tomography (SPECT) and fluorodeoxyglucose positron emission tomography (FDG-PET), may improve diagnostic accuracy [14, 27, 31-33] (Table 3). The detection of Epstein-Barr virus DNA in the CSF [26, 34] and toxoplasmosis serology can help differentiate CNS-Toxo from PCNSL [26]. However, histopathologic confirmation might still be needed for a definitive diagnosis of PCNSL [14, 31, 34].

\section{CNS toxoplasmosis}

\section{Epidemiology and clinical manifestations}

Toxoplasma gondii is an intracellular parasite that has traditionally been the most common etiological agent of focal CNS disease in patients with AIDS [35]. The relative incidence of CNS-Toxo decreased with improvements in treatment, from $72 \%$ in 1991 to $19 \%$ in 1996 [14].

The seroprevalence of antibodies against $T$. gondii in the general population varies substantially among different geographic locales, with a prevalence of approximately $11 \%$ in the United States and 50-80\% in certain European, Latin American, and African countries [11]. Humans may contract the infection by consuming food or water contaminated with oocysts or by eating undercooked meat (pork and lamb) containing tissue cysts. In patients with AIDS, CNS-Toxo primarily arises due to reactivation of latent infection, and the most common clinical feature is focal encephalitis. Patients may also present with nonfocal manifestations, including nonspecific headaches and psychiatric symptoms [11]. Most patients (> 80\%) who develop CNS-Toxo have serum CD4positive T lymphocyte counts of $<100$ cells $/ \mathrm{mm}^{3}$ [14].

A definitive diagnosis of CNS-Toxo requires a compatible clinical syndrome, identification of one or more mass lesions on computed tomography or MRI, and detection of the parasite in clinical samples [11]. In patients with severe immunosuppression, a negative result of anti $T$. gondii antibodies does not exclude the diagnosis of CNS-Toxo because up to $20 \%$ of patients with AIDS may not have detectable antibody titers [27].

In clinical practice, patients seropositive for $T$. gondii and CD4-positive T lymphocyte counts $<100$ cells $/ \mathrm{mm}^{3}$ may receive prophylaxis against CNS-Toxo. One study reported a clinical response to acute therapy with oral clindamycin and pyrimethamine in $90 \%$ of the patients with CNS-Toxo within 14 days $[11,36]$.

\section{MRI findings (Fig. 2)}

The characteristic MRI findings of CNS-Toxo are multiple masses, representing $T$. gondii abscesses of $2-3 \mathrm{~cm}$ in diameter, with ring contrast enhancement and edema (Table 3), however, single lesions are seen in 15-20\% of the cases [27]. The most common sites are the basal ganglia, thalamus,
Table 3 Radiological patterns of HIV-related CNS diseases with focal brain lesions $[14,27$, $31-33,37,45,54,61]$

\begin{tabular}{llll}
\hline Imaging technique & Toxoplasmosis & PCNSL & PML \\
\hline MRI findings & & & \\
CE & Yes & Yes & No \\
CE pattern & Ring & Homogenous or ring & No \\
Edema & Yes & Yes & No \\
Size & $<4 \mathrm{~cm}$ & $>4 \mathrm{~cm}$ & N/A \\
Location & Basal ganglia, thalamus, subcor- & Corpus callosum, & Mainly subcortical \\
& tical WM, cerebellum & periventricular WM & WM, cerebellar \\
Number of lesions & Multiple (occasionally solitary) & Multiple or Solitary & Multiple \\
& & & (occasionally solitary) \\
SPECT thallium-201 & Cold & Hot & Cold \\
FDG-PET & Hypometabolic & Hypermetabolic & Hypometabolic \\
\hline
\end{tabular}

$C E$ contrast enhancement, FDG fluorodeoxyglucose, $H I V$ human immunodeficiency virus, $M R I$ magnetic resonance imaging, PCNSL primary CNS lymphoma, PET positron emission tomography, $P M L$ progressive multifocal leukoencephalopathy, SPECT single-photon emission computed tomography, $W M$ white matter 
Fig. 2 Target sign on T2-weighted image and eccentric target sign on contrastenhanced T1-weighted image in a patient with HIV-related CNS toxoplasmosis. A mass lesion with surrounding edema was observed in the left lenticular nucleus. On T2-weighted image (a), the mass shows a concentric hyper- and hypointense zones with perilesional edema. On contrast-enhanced T1-weighted image (b), the mass shows a ring-shaped zone of peripheral contrast enhancement with a small eccentric nodule along the wall. Image $b$ is reprinted from [9] with permission

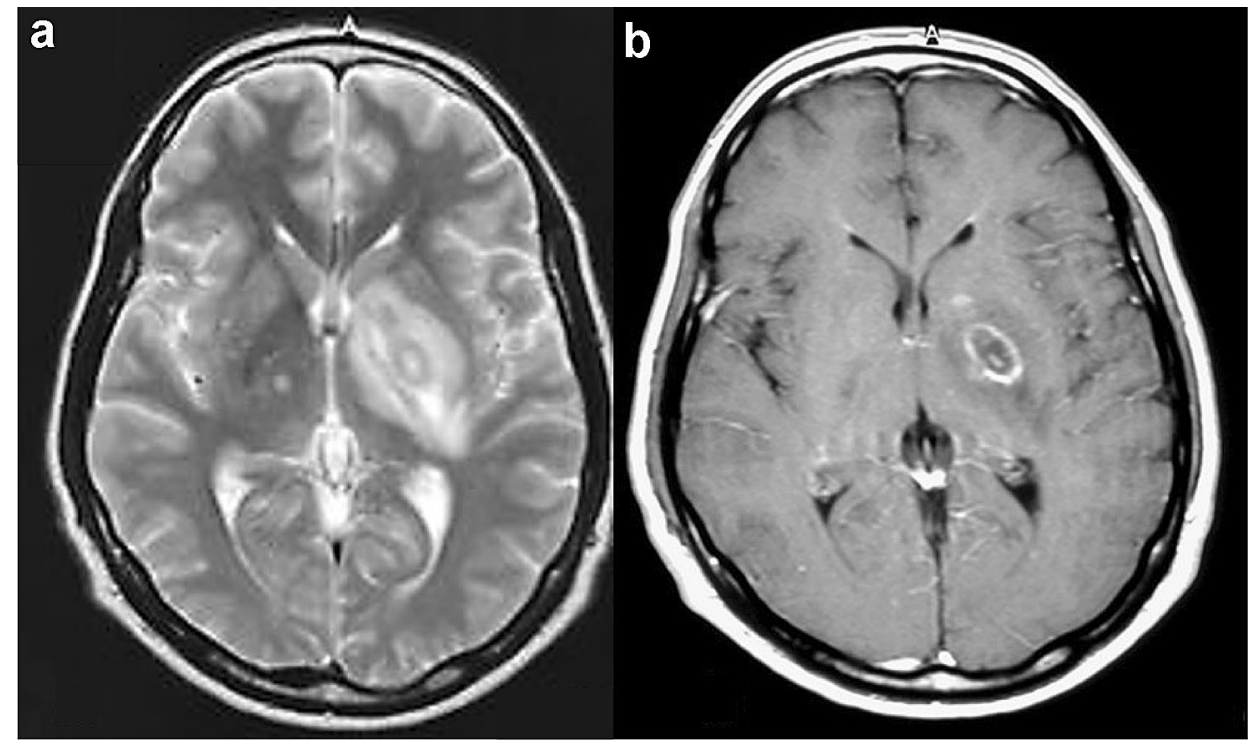

subcortical white matter, and cerebellum [27, 37]. Contrast enhancement may not be seen if the serum CD4-positive $\mathrm{T}$ lymphocyte count is $<50$ cells $/ \mathrm{mm}^{3}$. In rare cases, there is extensive encephalitis without abscess formation [35].

The pathognomonic signs for CNS-Toxo are a target sign on T2-weighted images and an eccentric target sign on contrast-enhanced T1-weighted images. The target sign is characterized by concentric high and low signal areas (Fig. 2a), and the number of concentric altered zones varies among reports [38]. The eccentric target sign is characterized by a ring-enhancing lesion with a contrast-enhanced eccentric nodule (Fig. 2b) [39, 40]. The ring corresponds to an inflammatory vascular zone at the edge of a necrotic lesion, and the nodule corresponds to a cluster of thickened vessels $[39,40]$. Target sign on T2-weighted images and eccentric target sign on contrast-enhanced T1-weighted image, however, have been observed in only one-third of the cases [31, 39, 40]. Different pathological findings associated with the degree of progression of abscess formation can explain the variety of CNS lesions [39].

\section{Primary CNS lymphoma}

\section{Epidemiology and clinical manifestations}

PCNSL accounts for up to $15 \%$ of non-Hodgkin lymphomas in HIV-infected individuals, and most cases are coinfected with the Epstein-Barr virus [34]. The incidence of PCNSL in HIV-infected individuals is $2-6 \%, 1,000$ times higher than that in the general population [41]. Affected patients typically have serum CD4-positive $\mathrm{T}$ lymphocyte counts $<50$ cells $/ \mathrm{mm}^{3}$ [42].

Although ART has decreased the incidence of HIVrelated PCNSL, it remains the most common HIV-associated malignancy [42]. Unless treated, the median survival of HIV-infected patients with PCNSL, after the onset of clinical symptoms, is 1 month [41]. With chemotherapy, the median survival increases to 1.5 years $[34,43]$. Owing to the rapid progression of the disease, a fast and reliable diagnosis is essential. However, the patients can be asymptomatic or have imperceptible neurologic symptoms [34]. Stereotactic biopsy, CSF testing, cytology, or a combination of these methods are used to diagnose HIV-related PCNSL [34, 44], however, in patients who otherwise have typical clinical and imaging findings, detection of Epstein-Barr virus DNA in the CSF favors the diagnosis of PCNSL.

\section{MRI findings (Fig. 3)}

HIV-related PCNSL is characterized by lesions with a larger diameter $(\geq 4 \mathrm{~cm})$ than that of CNS-Toxo, with an almost equal likelihood of multiple and solitary lesions [45], they most commonly involve the basal ganglia and corpus callosum [46].

PCNSLs exhibit variable imaging findings based on the patients' immune status [30]. HIV-related PCNSL is more aggressive than that in immunocompetent patients, and more frequently exhibits central necrosis and spontaneous hemorrhage [30]. When the lesions exhibit necrosis and/or hemorrhage, contrast enhancement is often irregular or peripheral, forming a ring-like enhancement similar to that seen in CNSToxo (Fig. 3). It is reported in up to $75 \%$ of cases [46], and therefore, differentiating HIV-related PCNSL from CNSToxo on conventional MRI can be a diagnostic challenge.

Some additional MR techniques, such as diffusionweighted imaging (DWI) [47], MRS [48], and perfusion MR imaging $[49,50]$ are reportedly useful in differentiating HIV-related PCNSL from CNS-Toxo, with a lower apparent 


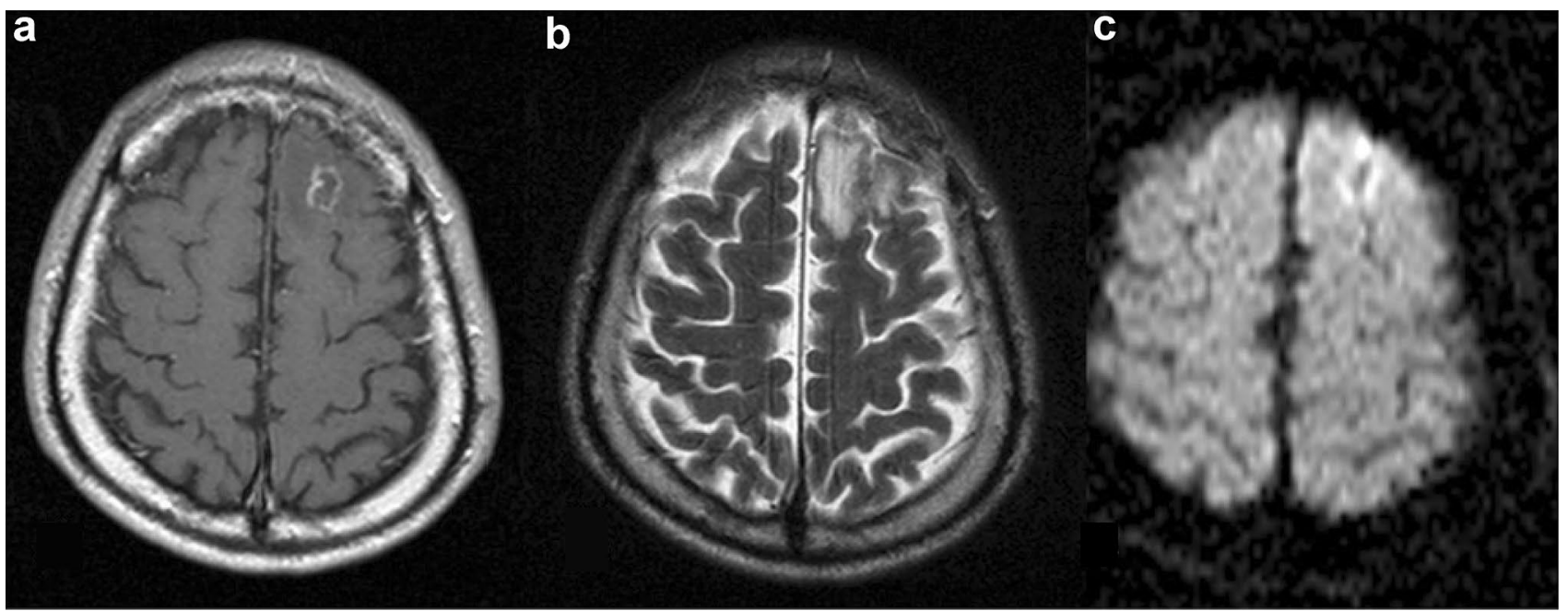

Fig. 3 Ring-enhanced lesion in a patient with HIV-related primary CNS lymphoma. Contrast-enhanced T1-weighted image (a) shows a ring-enhanced lesion in the left frontal subcortical white matter. The

diffusion coefficient (ADC) value [47], higher choline/creatinine ratio [48], and higher regional cerebral blood volume (rCBV) in patients with HIV-related PCNSL [50].

However, these findings should be interpreted with caution; particularly, regarding tissue heterogeneity within the lesion caused by necrosis and hemorrhage [49-52]. There is a significant overlap, even in reports wherein DWI-derived ADC values proved statistically useful for differentiation $[47,51]$. The authors speculated that necrotic lesions in HIV-related PCNSL are less likely to show restricted diffusion owing to their relative hypocellularity caused by necrosis [51]. When a HIV-related PCNSL lesion is necrotic, portions of the lesion that remain highly cellular may show restricted diffusion, whereas the necrotic portions of the lesion do not [51]. Overlapping MRS findings between HIVrelated PCNSL and CNS-Toxo have also been reported [52]. The authors speculated that the primary reason for the overlap is that central necrosis in HIV-related PCNSL lesions has a composition similar to that of a necrotic abscess in CNS-Toxo [52]. Tissue inhomogeneity within lesions tends to diminish the specificity of the spectrum [52]. In perfusion MRI, the maximum rCBV is more significant compared with the mean $\mathrm{rCBV}$, which is more susceptible to internal heterogeneity [50].

On thallium-201 SPECT, HIV-related PCNSL shows higher thallium-201 uptake than that of CNS-Toxo [14]. In addition, FDG uptake in HIV-related PCNS is higher than that in CNS-Toxo [31]. However, the accuracy of thallium-201 SPECT and FDG-PET can be affected due to several factors, including the size and location of the lesion and the presence of necrotic and hemorrhagic areas within the tumor $[14,31]$. mass shows a heterogeneous signal on T2-weighted image (b) with surrounding edema. On diffusion-weighted image (c), the lesion shows peripheral hyperintensity

Although these advanced MR techniques and nuclear medicine examinations can aid in diagnosis, a stereotactic biopsy should be performed when the diagnosis is ambiguous, despite with clinical and laboratory findings [53].

\section{Progressive multifocal leukoencephalopathy}

\section{Epidemiology and clinical manifestations}

PML is a subacute progressive demyelinating disease caused by oligodendrocyte damage resulting from infection with JC virus [54], which has a worldwide distribution and seroprevalence of 39-69\% among adults in the general population. Primary JC virus infection usually occurs asymptomatically in childhood, resulting in a chronic asymptomatic carrier state [55], however, it can reactivate in a state of severe immunosuppression. In this setting, neurotropic variants that can replicate in the glial cells may form [56]. Then, the virus spreads to the brain and induces a lytic infection of oligodendrocytes, which are myelin-producing cells [56].

HIV infection is strongly associated with PML; during the AIDS pandemic, it developed in 5\% of HIV-infected individuals. This association might, in part, be explained by the synergistic effect of HIV and JC virus co-infection. Outside the context of HIV infection, PML characteristically manifests as a complication of other immunocompromising conditions. In the past 4 decades in Western countries, HIV infection accounted for approximately $80 \%$ of PML cases [57], whereas in Japan, HIV infection accounted for onethird of PML cases [58]. Based on postmortem data, the prevalence of PML in patients with AIDS was between 2.4 and $5.3 \%$ [14]. 
No specific therapy exists for JC virus infection or HIVrelated PML. The primary therapeutic approach involves ART to reverse immunosuppression that interferes with the normal host response to JC virus [55]. Unless treated, HIV-related PML results in death within approximately 2.5-4.0 months of disease onset [14]. With ART, survival in patients with HIV-related PML has extended to years [54, 55, 57]. Among survivors of HIV-related PML, 44\%-83\% achieve clinical stabilization or some improvement if ART was initiated early in the disease course. However, many long-term survivors are left with substantial morbidityapproximately $70 \%$ experience some residual neurological disability, which is moderate to severe in $25-50 \%$ of cases. Up to $44 \%$ of survivors experience seizures [57]. Thus, early diagnosis and prompt initiation of ART are key factors for preserving neurological function in patients with PML [54].

PML has an insidious onset and steady subacute progression and manifests as focal neurological deficits. Since demyelinating lesions can involve any region in the brain, neurological disabilities vary from patient to patient. However, a common finding is that the symptoms worsen daily due to the progression and spread of demyelinating lesions [55].

\section{MRI findings (Figs. 4, 5)}

MRI is a powerful tool for the diagnosis of PML. Diagnostic criteria, based on clinical, MRI, and CSF findings, have been broadly adopted, in addition to classical histopathological criteria $[57,59]$.

MRI appears as distinct white matter lesions in areas of the brain that correspond to neurological symptoms. Without therapy, the lesions expand subacutely and are accompanied by the worsening of clinical symptoms [54, 57]. The diagnostic classification includes several levels of certainty (Table 4) [59]. When typical clinical and MRI findings are present, the diagnosis of PML can be based on the presence of JC virus DNA in the CSF [57].

The characteristic MRI finding for PML is the presence of asymmetrically located white matter lesions. The lesions show a low signal on T1-weighted image and a high signal on T2-weighted images [59]. Contrast enhancement is generally negative, but faint enhancement may be seen at lesion margins [60]. It may be challenging to differentiate PML from other diseases, such as gliomatosis or multiple sclerosis with imaging findings alone. However, subacute lesion progression on repeat MRI accompanied by worsening clinical symptoms and the uniquely uneven degree of demyelination within the lesion is often shown in PML [54, 57].

Although demyelination by JC virus can occur anywhere oligodendrocytes exist, the lesions often first appear in the subcortical white matter of the cerebrum, including in the short-range association fibers (also called U-fibers) [54]. The lesions are often distributed asymmetrically, and even when the distribution is bilateral and symmetrical, the degree of demyelination is asymmetrical (Fig. 4) [54]. Demyelination spreads outwards, from the lesion to the surrounding area.

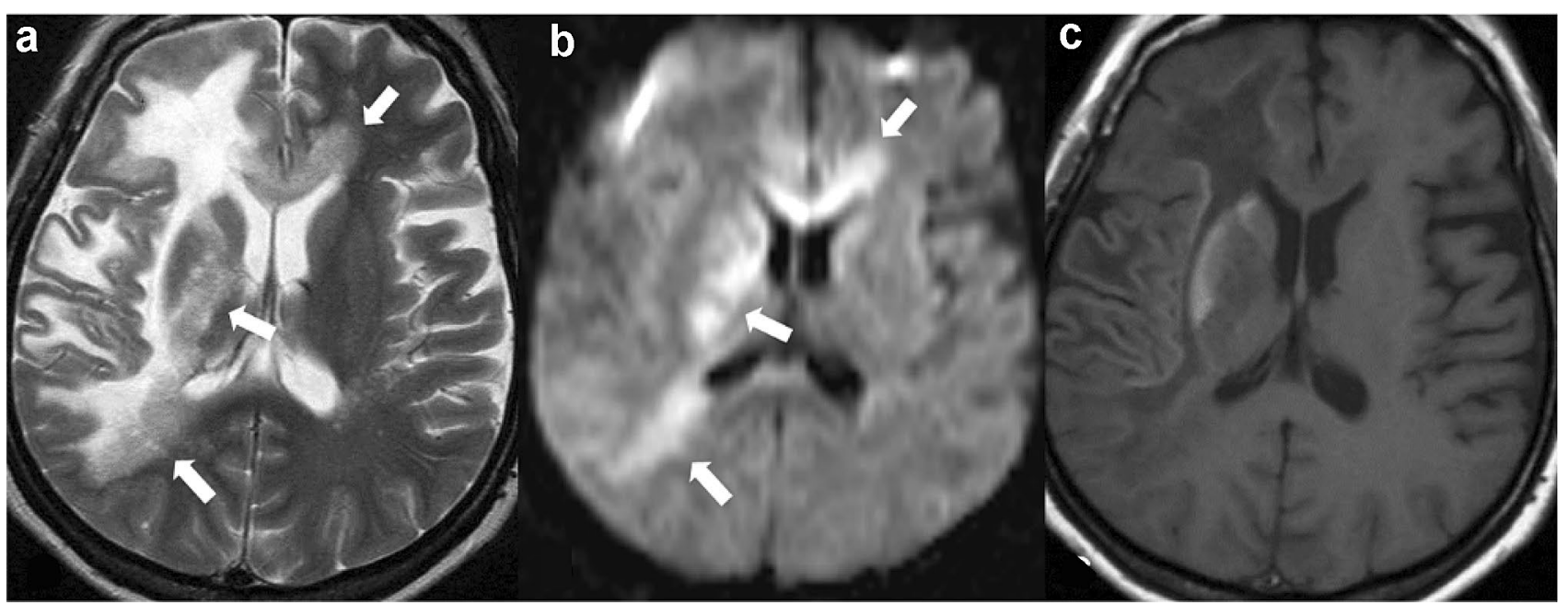

Fig. 4 Heterogeneous demyelination in a patient with HIV-related progressive multifocal leukoencephalopathy. On T2-weighted image (a), the older demyelinated lesion shows homogenous hyperintensity, while its medial margin, frontline (white arrows), shows heterogeneous pale hyperintensity with numerous punctate hyperintensities (milky way appearance). On diffusion-weighted image (b), the hyperintensity area (DW hyperintensity rim) corresponding to the milky way appearing area is shown. On T1-weighted image (c), hyperintensity is seen in the right head of the caudate nucleus, putamen, and subcortical area. They are adjusted to a large confluent demyelinated area showing homogenous hyperintensity on T2-weighted image (a) and hypointensity on T1-weighted image (c). The image a and b were reprinted from [9] with permission 
Fig. 5 Lesion progression in a patient with HIV-related progressive multifocal leukoencephalopathy. T2-weighted (a, b), T1-weighted (c, d), and contrast-enhanced T1-weighted (e, f) images acquired 2 months (a, c, e) and 3 months $(\mathbf{b}, \mathbf{d}, \mathbf{f})$ after the initial symptom of facial palsy. The first T2-weighted image (a) shows numerous dots with pale hyperintense lesions (milky way appearance) involving the bilateral frontal white matter predominantly on the right. The first T1-weighted image (c) shows hypointense lesions corresponding to advanced demyelination in right subcortical white matter. The second images $(\mathbf{b}, \mathbf{d}, \mathbf{f})$ show more expansive lesions with more advanced demyelination than the first images (a, c, e). Milky way appearance is more prominent in the left frontal white matter on the second T2-weighted image (b) than on the first T2-weighted image (a)

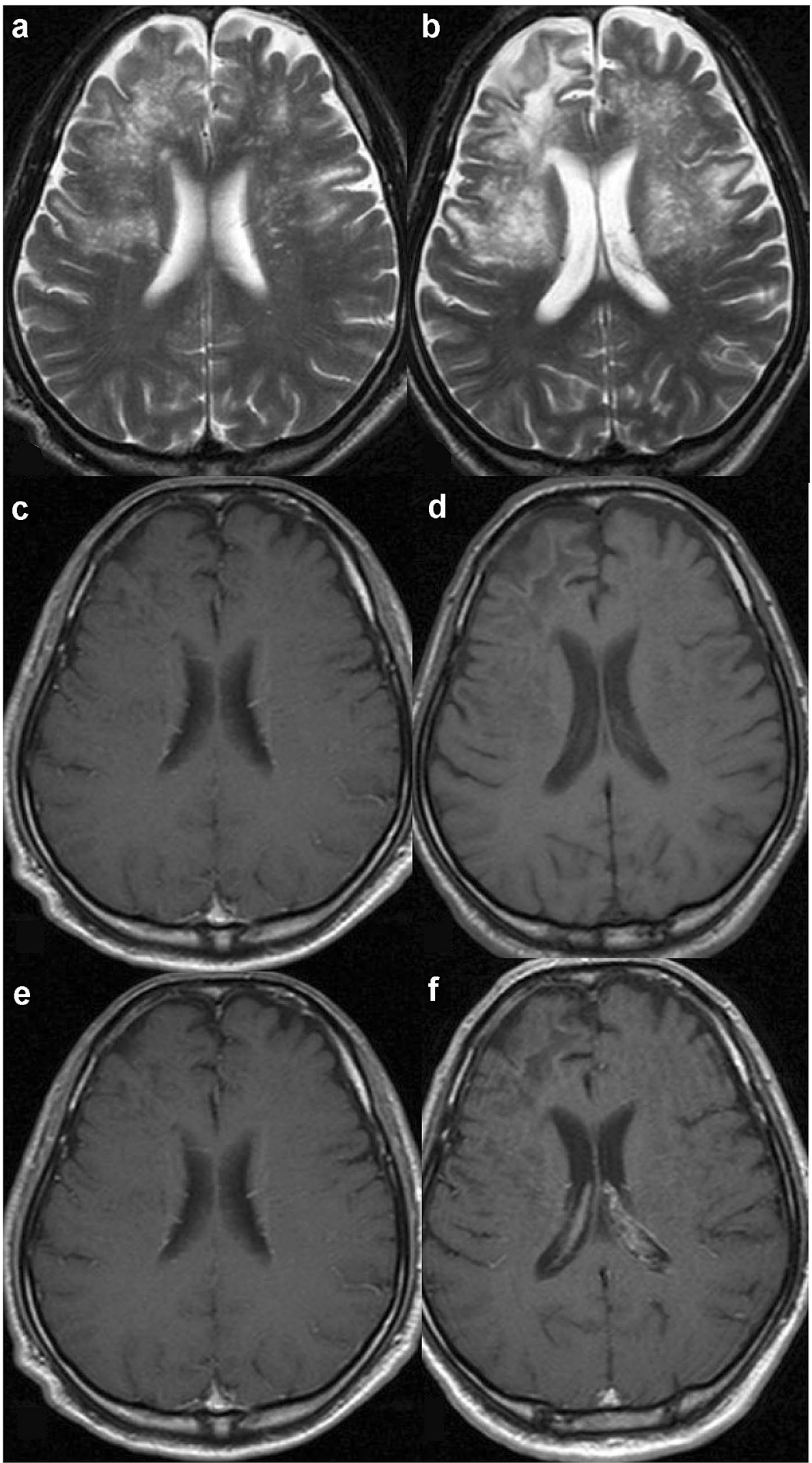


Table 4 Summary of the diagnostic criteria for PML $[57,59]$

\begin{tabular}{lcccc}
\hline $\begin{array}{l}\text { Certainty of PML } \\
\text { diagnosis }\end{array}$ & $\begin{array}{l}\text { Compatible clini- } \\
\text { cal features }\end{array}$ & $\begin{array}{l}\text { Compatible MRI } \\
\text { findings }\end{array}$ & $\begin{array}{l}\text { CSF PCR for } \\
\text { JC virus }\end{array}$ & $\begin{array}{l}\text { Alternative diagnoses } \\
\text { are clinically excluded }\end{array}$ \\
\hline Definite & + & + & + & + \\
Probable & + & - & + & + \\
& - & + & + & + \\
Possible & + & - & + & + \\
& - & - & - & + \\
Not PML & - & - & - & - \\
& + & + & - & - \\
\hline
\end{tabular}

+indicates present, -indicates absence

$C S F$ cerebrospinal fluid, JCV JC virus, $N D$ not done or equivocal result, $P C R$ polymerase chain reaction, PML progressive multifocal leukoencephalopathy
The newer, spreading demyelinating margin is called the frontline, whereas older portions of the lesions show advanced demyelination (Fig. 4a, b) [54]. The frontline margins on T2-weighted images show a diffuse pale hyperintensity and/or numerous discrete hyperintense dots giving a milky way appearance [54]. This often corresponds to the hyperintense rim on DWI (Fig. 4a, b) [27, 61]. In many cases, the hyperintense rim on DWI is interrupted at older demyelinated margins. With progression, the intensity gradually increases on T2-weighted images and coalesces to form a homogeneous advanced demyelinated lesion of near-CSF intensity (Fig. 5) [65].

The cerebral cortex and deep-gray matter bordering advanced demyelinated areas may show a high signal on T1-weighted images (Fig. 4c) [54, 62]. Hypointense signals may also be visualized on susceptibility-weighted imaging for deep layers of the cerebral cortex bordering advanced demyelinated areas $[63,64]$. These findings on T1-weighted and susceptibility-weighted images are not specific to PML or directly due to JC virus infection, but they may be secondary to demyelination [64].

\section{Meningitis/meningoencephalitis}

A wide range of pathogens can cause meningitis/meningoencephalitis in HIV-infected patients, but here, we will discuss CNS-Crypt and CNS-TB, because of their impact on acute mortality. Although the overall prognosis of HIV-related CNS-Crypt and CNS-TB has improved since the introduction of ART, acute mortality has not changed significantly over time, ranging 6-16\% for CNS-Crypt [66-70] and at $30 \%$ for CNS-TB [71].

If HIV-infected patients have unexplained fever, especially those with severe immunosuppression, these disorders should be actively suspected and investigated immediately [71, 72]. Both CNS-Crypt and CNS-TB are diagnosed by pathogen detection in the CSF. When meningitis is suspected in HIV-infected patients, CSF should be tested for antibodies against pathogens causing both diseases [73]. Since both CNS-Crypt and CNS-TB usually disseminate from lung lesions, chest computed tomography and radiography may trigger the diagnosis [27, 72, 74-77]. Combining CSF pathogen testing with chest imaging may confirm the suspicion and allow early treatment initiation $[74,77]$.

\section{CNS-Crypt}

\section{Epidemiology and clinical manifestations}

HIV infection is the most common risk factor for cryptococcosis caused by Cryptococcus neoformans. Although Cryptococcus gattii is the other primary cause of cryptococcosis in humans, it is mainly reported in immunocompetent individuals exposed to plant propagules found in tropical and subtropical regions [77-81]. Cryptococcus spp. enters the body by inhalation, and in most cases, is eliminated by host defense mechanisms. However, in some cases, especially in HIV-infected immunocompromised individuals, it may lead to pneumonia and subsequent CNS dissemination, causing meningoencephalitis. Although HIV infection is the major risk factor for CNS-Crypt, spread to the CNS is also observed in immunocompromised HIV-negative and immunocompetent individuals [77].

HIV-related CNS-Crypt occurs when the serum CD4positive T lymphocyte cell count drops below $50-100$ cells/ $\mathrm{mm}^{3}$ [82]. HIV-related CNS-Crypt is characterized by a low-grade inflammatory response [83]. Therefore, symptoms other than fever are often minimal and meningococcal irritation is often absent $[72,83]$. 
Fig. 6 Dilated periventricular space in a patient with HIVrelated CNS Cryptococcosis. T2-weighted image (a) shows clustered innumerable hyperintense cysts, characteristic of cryptococcal gelatinous pseudocysts, bilaterally in the lentiform nuclei and head of the caudate nucleus and thalamus. Some of them show contrast enhancement on contrast-enhanced T1-weighted image (b, arrows)

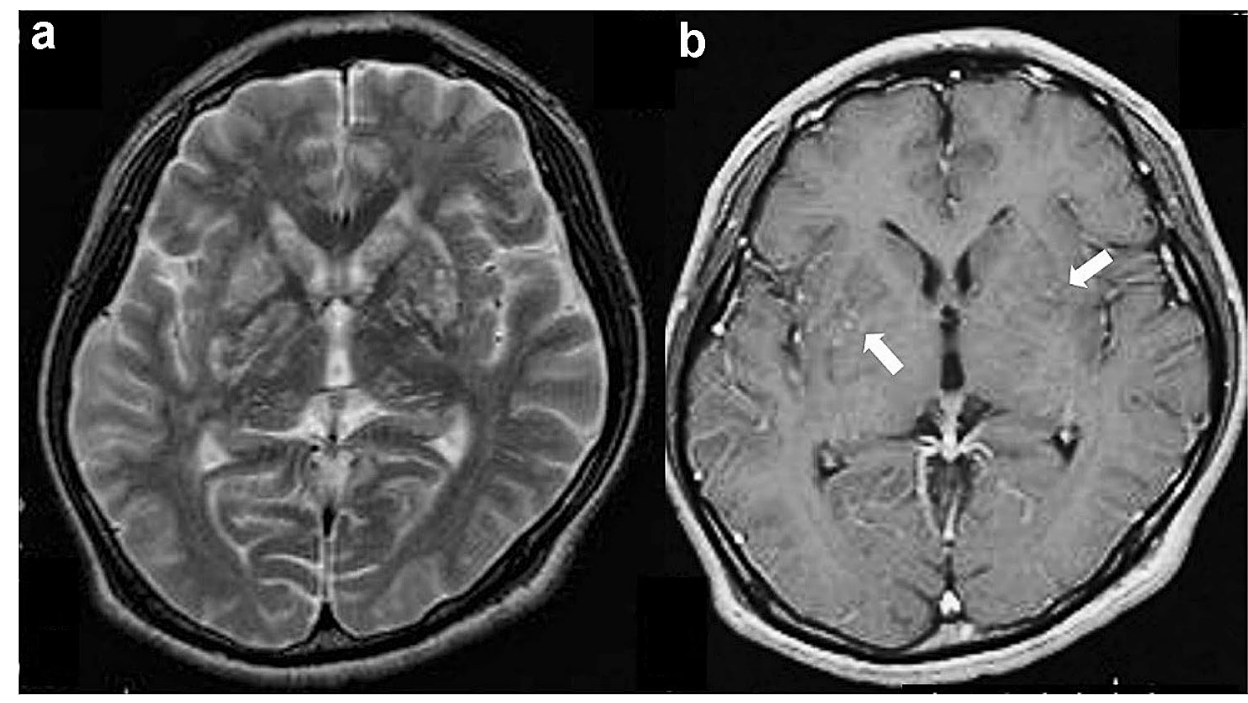

\section{MRI findings (Fig. 6)}

The radiologic manifestations of CNS-Crypt vary and are frequently minimal $[27,84]$. MRI findings are nonspecific or, most often, normal [85]. In HIV-infected patients with fever, CNS-Crypt should be considered irrespective of positive or negative MRI findings [43].

The positive imaging findings in CNS-Crypt correspond to three main forms meningitis/meningoencephalitis, gelatinous pseudocysts, and a granuloma called cryptococcoma. Among them, meningitis/meningoencephalitis and gelatinous pseudocysts are seen in HIV-related CNS-Crypt. Mass lesions called cryptococcoma due to C. neoformans are rarely seen in patients who are not receiving ART [27, 86].

Meningitis/meningoencephalitis is the primary lesion of CNS-Crypt and is pronounced at basal cisterns. If the meningeal infection spreads along the perivascular spaces, gelatinous mucoid-like cryptococcal capsular polysaccharides and budding yeast accumulate within dilated perivascular spaces and gives rise to small cysts called gelatinous pseudocysts. These cysts exhibit a "soap bubble appearance" on MRI, with a low to intermediate signal on T1-weighted images, a high signal on T2-weighted images, and a low signal on FLAIR images [87]. Gelatinous pseudocysts are often found in the basal ganglia, thalamus, and midbrain. In patients with severe immunosuppression, the only positive imaging findings indicating CNS-Crypt are mild/non-enhancing cystic lesions and meninges and bilateral symmetrical perivascular space enlargement (Fig. 6) [43].

When there is some degree of the immune response, such as when ART has already been administered, imaging may show cryptococcoma and nodular meningeal enhancement similar to that seen in granulomatous diseases (e.g., tuberculosis, syphilis, and sarcoidosis) and carcinomatous meningitis $[27,86]$.

\section{CNS tuberculosis}

\section{Epidemiology and clinical manifestations}

CNS-TB is caused by Mycobacterium tuberculosis, disseminated through the bloodstream from the tuberculosis foci in the lungs. Although the most common manifestations of CNS-TB are meningitis, tuberculoma and abscess are not unusual (occurring in approximately 25 and $20 \%$ of the cases, respectively) and can be seen separately or simultaneously [27, 88]. HIV-infected individuals are up to 20 times more likely to fall ill with TB. In 2017, 10 million people developed TB globally, 9\% of whom had HIV [89].

\section{MRI findings (Figs. 7, 8)}

In patients with CNS-TB with meningitis, classic neuroimaging findings include hydrocephalus $(75 \%)$, basilar exudates (38\%), periventricular infarcts (15-30\%), and cerebral parenchymal tuberculomas (5-10\%), which might be seen separately or simultaneously [88, 90-92]. Although imaging findings in HIV and non-HIV-associated CNS-TB are almost similar, meningitis is more frequent in those infected with HIV. In a study of 2205 patients with TB, $10 \%$ of the HIV-positive patients had TB meningitis, compared with only $2 \%$ of the non-infected HIV patients [93]. In contrast to CNS-Crypt, CNS-TB frequently shows hydrocephalus (similar to non-HIV-related CNS-TB) [43] and meningeal contrast enhancement, especially in the basal cisterns (Fig. 7a) [27], their presence is strongly suggestive of tuberculous meningitis [91, 92]. On contrastenhanced T1-weighted images, tuberculomas with caseous necrosis show a ring-shaped contrast enhancement, whereas those without caseous necrosis show homogeneous contrast enhancement (Fig. 7b, c) [27]. 


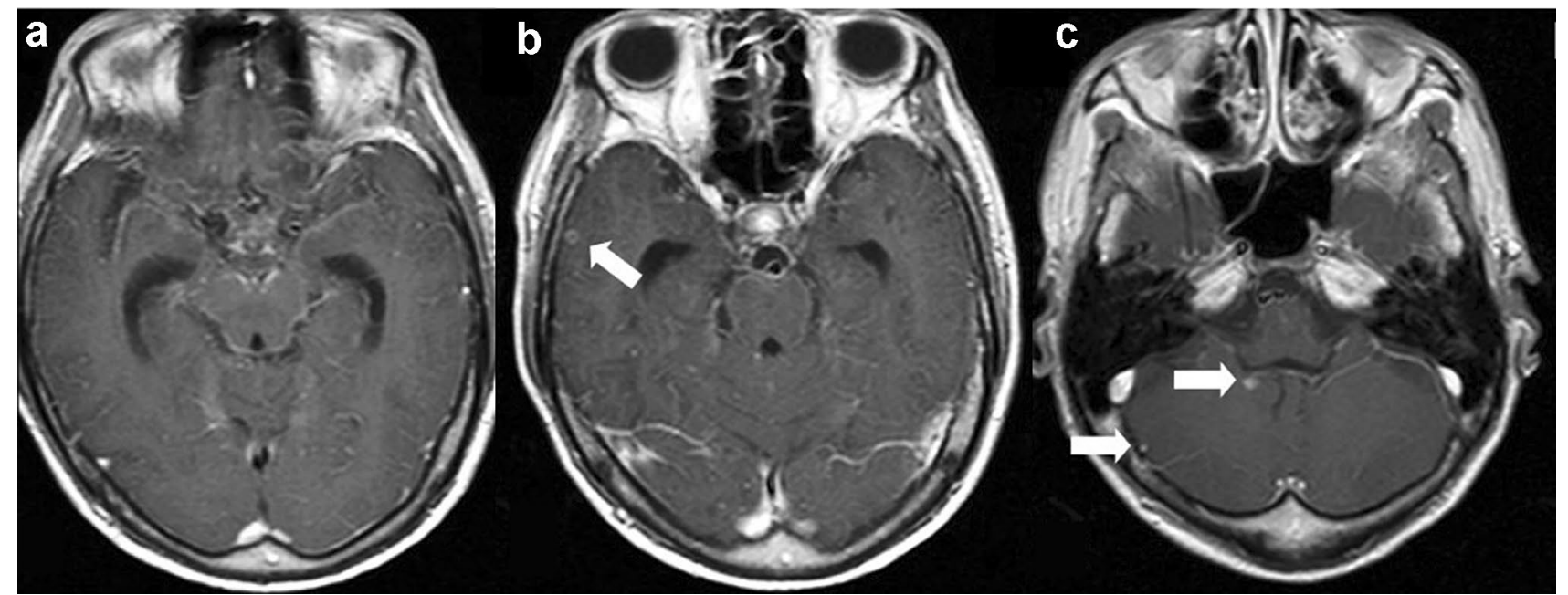

Fig. 7 Basilar meningitis and tuberculoma in a patient with HIVrelated CNS tuberculosis. Contrast-enhanced T1-weighted image of the basal cistern level (a) shows contrast enhancement along the mid- brain, and medial temporal lobe representing meningitis. Peripherally located contrast-enhanced nodules representing tuberculomas are also shown (b, c, arrows)
Fig. 8 Acute infarction caused by tuberculosis meningitis in a patient with HIV infection. Hyperintensity on T2-weighted image (a) is shown in the bilateral basal ganglia with slight swelling. The lesion shows hyperintensity on diffusionweighted image corresponding to acute infarction (b). Enlargement of the bilateral lateral ventricle revealing hydrocephalus was also noted

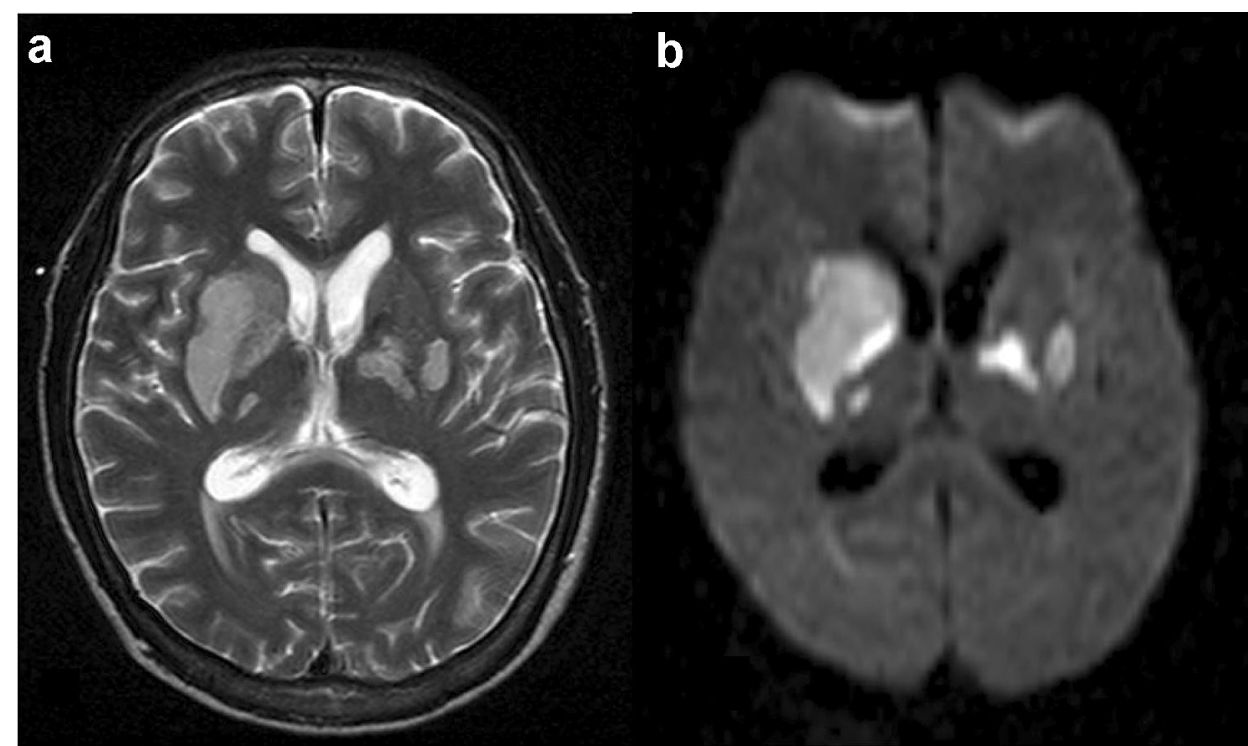

Inflammation can also involve blood vessels, and impaired circulation and vasospasm may lead to infarction, which is often bilateral in the basal ganglia (Fig. 8) [94].

\section{Immune reconstitution inflammatory syndrome}

Iyndrome is a major complication related to ART and is a consequence of excessive activation of the immune system against persistent antigens (paradoxical IRIS), viable pathogens (unmasking IRIS), or self-antigens $[95,96]$. The prevalence of IRIS ranges from 7.8 to $13 \%$ [86-88], and onset occurs 1-1.5 months after ART initiation [96]. Clinical factors associated with IRIS development are a serum CD4positive T lymphocyte count of $<50$ cells $/ \mathrm{mm}^{3}$ and HIVRNA levels greater than $1.0 \times 10^{5}$ copies $/ \mathrm{mL}$ (high viral load) at the time of ART initiation [96].

\section{CNS-IRIS}

\section{Epidemiology and Clinical Manifestations}

CNS-IRIS has an acute onset and it rapidly progresses from symptom onset to death [97]. The syndrome may be recognized by the development of new or worsening of existing clinical symptoms (e.g., OIs) despite adequate treatment and serological response. Specific abnormalities can be found on 
Fig. 9 Immune reconstitution inflammatory syndrome (IRIS) developed in a patient with progressive multifocal leukoencephalopathy. FLAIR image (a) shows white matter lesions due to PML. Contrast-enhanced T1-weighted image (b) shows parenchymal and perivascular enhancement (b) compatible with IRIS

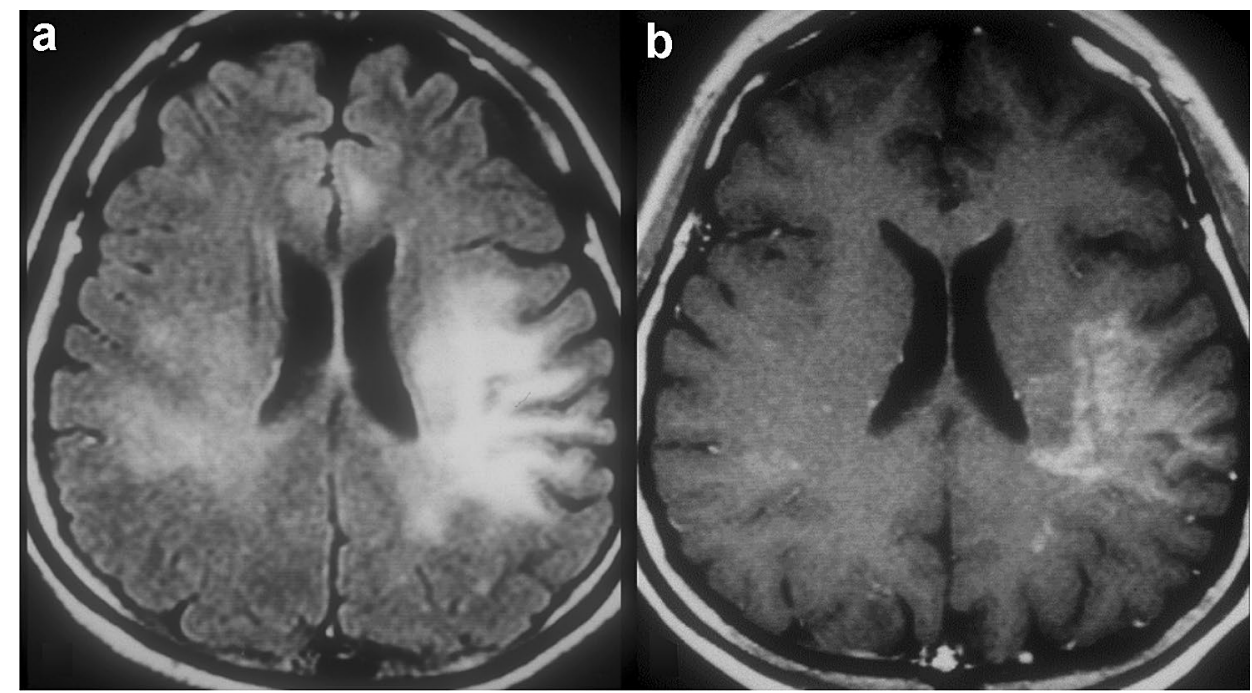

MRI or computed tomography images [98]. Glucocorticosteroids may be used in patients with severe IRIS symptoms [99]. Patients should also be monitored for other OIs that may develop during therapy.

Among HIV-related CNS diseases, PML and CNS-Crypt are the most frequently encountered diseases. IRIS develops in at least $18 \%$ of HIV-infected patients with PML after starting ART [95]. As ART is the only effective therapy for PML, dealing with IRIS is especially difficult in these patients [95]. In patients with HIV-related CNS-Crypt, IRIS is estimated to occur in $16.7 \%$ of patients after ART initiation [99, 100]. Less frequently reported pathogens associated with CNS-IRIS are varicella-zoster virus, cytomegalovirus, Candida spp., Mycobacterium tuberculosis, and Toxoplasma gondii [96, 101]. Although not in the brain, IRIS develops in more than one-third of patients with retinitis caused by cytomegalovirus [96].

\section{MRI findings (Fig. 9)}

On MRI, the presence of an enhanced area on contrastenhanced T1-weighted images, a transient increase in parenchymal abnormalities with a high signal on T2-weighted or FLAIR images, mass effect, and peripherally restricted diffusion on DWI can be valuable clues to diagnose CNSIRIS (Fig. 9) [95]. However, a negative MRI finding alone should not exclude the diagnosis [95]. Although CNS-IRIS is a diagnosis of exclusion, MRI can be pivotal for early recognition and improved prognosis [95]. In addition, a contrast-enhancing effect is not always associated with a poor prognosis [102]. In some studies, contrast enhancement was reported to be associated with a good prognosis [103]. These findings might indicate immune recovery, and careful monitoring of the clinical course along with imaging findings is recommended.

\section{Extra-CNS findings on brain MRI}

During brain MRI reading, attention should also be paid to the cranial bone and extracranial lesions, particularly those involving the bone marrow, parotid glands, lymphoid tissue, and skin. HIV causes chronic inflammation and hyperplasia of the bone marrow [104-106], both of which could result in a decreased signal on T1-weighted images, making the bone marrow appear "gray" [107]. In addition, HIV and ART both increase the risk of osteoporosis [108]. The frequency of parotid lesions in HIV-infected patients is reported to be $1-10 \%$, and in some cases distinguishing them from other bilateral parotid tumors, such as Warthin cysts, is difficult [109]. Kaposi's sarcoma, a vascular neoplasm caused by human herpesvirus type eight, is the most common AIDS-related malignancy and is often found in the head and neck area.

\section{Conclusions}

In summary, HIV encephalopathy shows a diffuse bilateral pattern, whereas PML, PCNSL, and CNS-Toxo show focal patterns on MRI. Among meningitis/meningoencephalitis, that have extremely poor prognosis, CNS-Crypt commonly shows no abnormalities on imaging, while in many cases, CNS-TB shows findings suggestive of meningitis. CNS-IRIS displays distinct MRI findings of the offending OIs. With this knowledge, radiologists may play a pivotal role in the early recognition of HIV-related CNS diseases and thus contribute to a better prognosis for patients. 
Funding The authors received no specific grant from any funding agency in the public, commercial, or not-for-profit sectors.

\section{Declarations}

Conflict of interest The authors declare that they have no conflict of interest.

Ethical approval This article does not contain any studies with human participants or animals performed by any of the authors.

Open Access This article is licensed under a Creative Commons Attribution 4.0 International License, which permits use, sharing, adaptation, distribution and reproduction in any medium or format, as long as you give appropriate credit to the original author(s) and the source, provide a link to the Creative Commons licence, and indicate if changes were made. The images or other third party material in this article are included in the article's Creative Commons licence, unless indicated otherwise in a credit line to the material. If material is not included in the article's Creative Commons licence and your intended use is not permitted by statutory regulation or exceeds the permitted use, you will need to obtain permission directly from the copyright holder. To view a copy of this licence, visit http://creativecommons.org/licenses/by/4.0/.

\section{References}

1. World Health Organization. 2007 WHO case definitions of HIV for surveillance and revised clinical staging and immunological classification of HIV-related disease in adults and children. https://www.who.int/hiv/pub/guidelines/HIVstaging150307.pdf. Accessed on 15 May 2021.

2. Ellis R, Langford D, Masliah E. HIV and antiretroviral therapy in the brain: neuronal injury and repair. Nat Rev Neurosci. 2007;8:33-44.

3. Saylor D, Dickens AM, Sacktor N, Haughey N, Slusher B, Pletnikov M, et al. HIV-associated neurocognitive disorderpathogenesis and prospects for treatment. Nat Rev Neurol. 2016;12:234-48.

4. Nakagawa M. HIV infection and neurological complications. Nippon Naika Gakkai Zasshi. 2008;97:1690-6.

5. Gray F, Chrétien F, Vallat-Decouvelaere AV, Scaravilli F. The changing pattern of HIV neuropathology in the HAART era. J Neuropathol Exp Neurol. 2003;62:429-40.

6. Garvey L, Winston A, Walsh J, Post F, Porter K, Gazzard B, et al. HIV-associated central nervous system diseases in the recent combination antiretroviral therapy era. Eur J Neurol. 2011;18:527-34.

7. UNAIDS. 2020 UNAIDS DATA 2020: Joint United Nations Programme on HIV/AIDS, UNAIDS data 2020. Accessed on 28 April 2021.

8. Iacob SA, Iacob DG, Jugulete G. Improving the adherence to antiretroviral therapy, a difficult but essential task for a successful hiv treatment-clinical points of view and practical considerations. Front Pharmacol. 2017;8:831.

9. Sakai M. AIDS related brain diseases. In: Hosoya T, Korogi Y, Miki Y, Yamada K, editors. MRI of the brain. Tokyo: Medical Science International; 2015. p. 422-32.

10. Jung AC, Paauw DS. Diagnosing HIV-related disease: using the CD4 count as a guide. J Gen Intern Med. 1998;13:131-6.

11. 2017 Panel on opportunistic infections in adults and adolescents with HIV. Guidelines for the prevention and treatment of opportunistic infections in HIV-infected adults and adolescents: Toxoplasma gondii Encephalitis. Accessed on 11 Mar 2021.

12. 2020 Panel on opportunistic infections in adults and adolescents with HIV. Guidelines for the prevention and treatment of opportunistic infections in adults and adolescents with HIV. Accessed on 11 Mar 2021.

13. Masliah E, DeTeresa RM, Mallory ME, Hansen LA. Changes in pathological findings at autopsy in AIDS cases for the last 15 years. AIDS. 2000;14:69-74.

14. Skiest DJ. Focal neurological disease in patients with acquired immunodeficiency syndrome. Clin Infect Dis. 2002;34:103-15.

15. Abidin AZ, Dsouza AM, Nagarajan MB, Wang L, Qiu X, Schifitto G, et al. Alteration of brain network topology in HIV-associated neurocognitive disorder: a novel functional connectivity perspective. Neuroimage Clin. 2017;17:768-77.

16. Langford TD, Letendre SL, Marcotte TD, Ellis RJ, McCutchan JA, Grant I, et al. Severe, demyelinating leukoencephalopathy in AIDS patients on antiretroviral therapy. AIDS. 2002;16:1019-29.

17. Clifford DB, Ances BM. HIV-associated neurocognitive disorder. Lancet Infect Dis. 2013;13:976-86.

18. Antinori A, Arendt G, Becker JT, Brew BJ, Byrd DA, Cherner M, et al. Updated research nosology for HIV-associated neurocognitive disorders. Neurology. 2007;69:1789-99.

19. Ku NS, Lee Y, Ahn JY, Song JE, Kim MH, Kim SB, et al. HIVassociated neurocognitive disorder in HIV-infected Koreans: the Korean NeuroAIDS Project. HIV Med. 2014;15:470-7.

20. Kinai E, Komatsu K, Sakamoto M, Taniguchi T, Nakao A, Igari $\mathrm{H}$, et al. Association of age and time of disease with HIV-associated neurocognitive disorders: a Japanese nationwide multicenter study. J Neurovirol. 2017;23:864-74.

21. Njamnshi AK, Bissek ACZ-K, Ongolo-Zogo P, Tabah EN, Lekoubou AZ, Yepnjio FN, et al. Risk factors for HIV-associated neurocognitive disorders (HAND) in sub-Saharan Africa: the case of Yaoundé-Cameroon. J Neurol Sci. 2009;285:149-53.

22. Bloch M, Kamminga J, Jayewardene A, Bailey M, Carberry A, Vincent $\mathrm{T}$, et al. A screening strategy for HIV-associated neurocognitive disorders that accurately identifies patients requiring neurological review. Clin Infect Dis. 2016;63:687-93.

23. Davies J, Everall IP, Weich S, McLaughlin J, Scaravilli F, Lantos PL. HIV-associated brain pathology in the United Kingdom: an epidemiological study. AIDS. 1997;11:1145-50.

24. Heaton RK, Clifford DB, Franklin DR Jr, Woods SP, Ake C, Vaida F, et al. HIV-associated neurocognitive disorders persist in the era of potent antiretroviral therapy: CHARTER Study. Neurology. 2010;75:2087-96.

25. Ellis RJ, Badiee J, Vaida F, Letendre S, Heaton RK, Clifford D, et al. CD4 nadir is a predictor of HIV neurocognitive impairment in the era of combination antiretroviral therapy. AIDS. 2011;25:1747-51.

26. Antinori A, Ammassari A, De Luca A, Cingolani A, Murri R, Scoppettuolo G, et al. Diagnosis of AIDS-related focal brain lesions: a decision-making analysis based on clinical and neuroradiologic characteristics combined with polymerase chain reaction assays in CSF. Neurology. 1997;48:687-94.

27. Smith AB, Smirniotopoulos JG, Rushing EJ. From the archives of the AFIP: central nervous system infections associated with human immunodeficiency virus infection: radiologic-pathologic correlation. Radiographics. 2008;28:2033-58.

28. Wu Y, Storey P, Cohen BA, Epstein LG, Edelman RR, Ragin AB. Diffusion alterations in corpus callosum of patients with HIV. AJNR Am J Neuroradiol. 2006;27:656-60.

29. Ances BM, Sisti D, Vaida F, Liang CL, Leontiev O, Perthen JE, et al. Resting cerebral blood flow: a potential biomarker of the effects of HIV in the brain. Neurology. 2009;73:702-8. 
30. Javadi S, Menias CO, Karbasian N, Shaaban A, Shah K, Osman A, et al. HIV-related malignancies and mimics: imaging findings and management. Radiographics. 2018;38:2051-68.

31. Marcus C, Feizi P, Hogg J, Summerfield H, Castellani R, Sriwastava $\mathrm{S}$, et al. Imaging in differentiating cerebral toxoplasmosis and primary CNS lymphoma with special focus on FDG PET/ CT. AJR Am J Roentgenol. 2020;216:157-64.

32. Ruiz A, Ganz WI, Post MJ, Camp A, Landy H, Mallin W, et al. Use of thallium-201 brain SPECT to differentiate cerebral lymphoma from toxoplasma encephalitis in AIDS patients. AJNR Am J Neuroradiol. 1994;15:1885-94.

33. Antinori A, De Rossi G, Ammassari A, Cingolani A, Murri R, Di Giuda D, et al. Value of combined approach with thallium-201 single-photon emission computed tomography and Epstein-Barr virus DNA polymerase chain reaction in CSF for the diagnosis of AIDS-related primary CNS lymphoma. J Clin Oncol. 1999;17:554-60.

34. Brandsma D, Bromberg JEC. Primary CNS lymphoma in HIV infection. Handb Clin Neurol. 2018;152:177-86.

35. Luft BJ, Remington JS. Toxoplasmic encephalitis in AIDS. Clin Infect Dis. 1992;15:211-22.

36. Luft BJ, Hafner R, Korzun AH, Leport C, Antoniskis D, Bosler $\mathrm{EM}$, et al. Toxoplasmic encephalitis in patients with the acquired immunodeficiency syndrome. Members of the ACTG 077p/ ANRS 009 Study Team. N Engl J Med. 1993;329:995-1000.

37. Miller RF, Hall-Craggs MA, Costa DC, Brink NS, Scaravilli F, Lucas SB, et al. Magnetic resonance imaging, thallium-201 SPET scanning, and laboratory analyses for discrimination of cerebral lymphoma and toxoplasmosis in AIDS. Sex Transm Infect. 1998;74:258-64.

38. Mahadevan A, Ramalingaiah AH, Parthasarathy S, Nath A, Ranga U, Krishna SS. Neuropathological correlate of the "concentric target sign" in MRI of HIV-associated cerebral toxoplasmosis. J Magn Reson Imaging. 2013;38:488-95.

39. Masamed R, Meleis A, Lee EW, Hathout GM. Cerebral toxoplasmosis: case review and description of a new imaging sign. Clin Radiol. 2009;64:560-3.

40. Kumar GGS, Mahadevan A, Guruprasad AS, Kovoor JME, Satishchandra P, Nath A, et al. Eccentric target sign in cerebral toxoplasmosis: neuropathological correlate to the imaging feature. $J$ Magn Reson Imaging. 2010;31:1469-72.

41. Young RJ, Ghesani MV, Kagetsu NJ, Derogatis AJ. Lesion size determines accuracy of thallium-201 brain single-photon emission tomography in differentiating between intracranial malignancy and infection in AIDS patients. AJNR Am J Neuroradiol. 2005;26:1973-9.

42. Gupta NK, Nolan A, Omuro A, Reid EG, Wang CC, Mannis G, et al. Long-term survival in AIDS-related primary central nervous system lymphoma. Neuro Oncol. 2017;19:99-108.

43. Terada H. HIV-related infectious diseases. nichidoku-iho. 2002;47:330-41.

44. Moulignier A, Lamirel C, Picard H, Lebrette MG, Amiel C, Hamidi M, et al. Long-term AIDS-related PCNSL outcomes with HD-MTX and combined antiretroviral therapy. Neurology. 2017;89:796-804.

45. Ciacci JD, Tellez C, VonRoenn J, Levy RM. Lymphoma of the central nervous system in AIDS. Semin Neurol. 1999;19:213-21.

46. Haldorsen IS, Espeland A, Larsson EM. Central nervous system lymphoma: characteristic findings on traditional and advanced imaging. AJNR Am J Neuroradiol. 2011;32:984-92.

47. Camacho DL, Smith JK, Castillo M. Differentiation of toxoplasmosis and lymphoma in AIDS patients by using apparent diffusion coefficients. AJNR Am J Neuroradiol. 2003;24:633-7.

48. Chang L, Miller BL, McBride D, Cornford M, Oropilla G, Buchthal S, et al. Brain lesions in patients with AIDS: H-1 MR spectroscopy. Radiology. 1995;197:525-31.
49. Dibble EH, Boxerman JL, Baird GL, Donahue JE, Rogg JM. Toxoplasmosis versus lymphoma: cerebral lesion characterization using DSC-MRI revisited. Clin Neurol Neurosurg. 2017;152:84-9.

50. Ernst TM, Chang L, Witt MD, Aronow HA, Cornford ME, Walot I, et al. Cerebral toxoplasmosis and lymphoma in AIDS: perfusion MR imaging experience in 13 patients. Radiology. 1998;208:663-9.

51. Schroeder PC, Post MJ, Oschatz E, Stadler A, Bruce-Gregorios J, Thurnher MM. Analysis of the utility of diffusion-weighted MRI and apparent diffusion coefficient values in distinguishing central nervous system toxoplasmosis from lymphoma. Neuroradiology. 2006; 48:715-20.

52. Chinn RJ, Wilkinson ID, Hall-Craggs MA, Paley MN, Miller RF, Kendall BE, et al. Toxoplasmosis and primary central nervous system lymphoma in HIV infection: diagnosis with MR spectroscopy. Radiology. 1995;197:649-54.

53. Gildenberg PL, Gathe JC Jr, Kim JH. Stereotactic biopsy of cerebral lesions in AIDS. Clin Infect Dis. 2000;30:491-9.

54. Sakai M, Inoue Y, Aoki S, Sirasaka T, Uehira T, Takahama S, et al. Follow-up magnetic resonance imaging findings in patients with progressive multifocal leukoencephalopathy: evaluation of long-term survivors under highly active antiretroviral therapy. Jpn J Radiol. 2009;27:69-77.

55. 2018 Panel on Opportunistic Infections in Adults and Adolescents with HIV. Guidelines for the prevention and treatment of opportunistic infections in HIV-infected adults and adolescents: progressive multifocal leukoencephalopathy/JC virus infection: recommendations from the centers for disease control and prevention, the National Institutes of Health, and the HIV Medicine Association of the Infectious Diseases Society of America. Accessed on 11 Mar 2021.

56. Kartau M, Sipilä JO, Auvinen E, Palomäki M, VerkkoniemiAhola A. Progressive multifocal leukoencephalopathy: current insights. Degener Neurol Neuromuscul Dis. 2019;9:109-21.

57. Cortese I, Reich DS, Nath A. Progressive multifocal leukoencephalopathy and the spectrum of JC virus-related disease. Nat Rev Neurol. 2021;17(1):37-51.

58. Nakamichi K, Mizusawa H, Yamada M, Kishida S, Miura Y, Shimokawa T, et al. Characteristics of progressive multifocal leukoencephalopathy clarified through internet-assisted laboratory surveillance in Japan. BMC Neurol. 2012;12:121.

59. Berger JR, Aksamit AJ, Clifford DB, Davis L, Koralnik IJ, Sejvar JJ, et al. PML diagnostic criteria: consensus statement from the AAN Neuroinfectious disease section. Neurology. 2013;80:1430-8

60. Thurnher MM, Post MJ, Rieger A, Kleibl-Popov C, Loewe C, Schindler E. Initial and follow-up MR imaging findings in AIDSrelated progressive multifocal leukoencephalopathy treated with highly active antiretroviral therapy. AJNR Am J Neuroradiol. 2001;22:977-84.

61. Bergui M, Bradac GB, Oguz KK, Boghi A, Geda C, Gatti G, et al. Progressive multifocal leukoencephalopathy: diffusionweighted imaging and pathological correlations. Neuroradiology. 2004;46:22-5.

62. Khoury MN, Alsop DC, Agnihotri SP, Pfannl R, Wuthrich C, Ho $\mathrm{ML}$, et al. Hyperintense cortical signal on magnetic resonance imaging reflects focal leukocortical encephalitis and seizure risk in progressive multifocal leukoencephalopathy. Ann Neurol. 2014;75:659-69.

63. Thurnher MM, Boban J, Rieger A, Gelpi E. Susceptibilityweighted MR Imaging hypointense rim in progressive multifocal leukoencephalopathy: the end point of neuroinflammation and a potential outcome predictor. AJNR Am J Neuroradiol. 2019;40:994-1000. 
64. Umino M, Maeda M, Ii Y, Tomimoto H, Sakuma H. Low-signalintensity rim on susceptibility-weighted imaging is not a specific finding to progressive multifocal leukoencephalopathy. J Neurol Sci. 2016;362:155-9.

65. Ono D, Shishido-Hara Y, Mizutani S, Mori Y, Ichinose K, Watanabe $\mathrm{M}$, et al. Development of demyelinating lesions in progressive multifocal leukoencephalopathy (PML): comparison of magnetic resonance images and neuropathology of post-mortem brain. Neuropathology. 2019;39:294-306.

66. Rajasingham R, Smith RM, Park BJ, Jarvis JN, Govender NP, Chiller TM, et al. Global burden of disease of HIV-associated cryptococcal meningitis: an updated analysis. Lancet Infect Dis. 2017;17:873-81.

67. Lortholary O, Poizat G, Zeller V, Neuville S, Boibieux A, Alvarez M, et al. Long-term outcome of AIDS-associated cryptococcosis in the era of combination antiretroviral therapy. AIDS. 2006;20:2183-91.

68. Brouwer AE, Rajanuwong A, Chierakul W, Griffin GE, Larsen RA, White NJ, et al. Combination antifungal therapies for HIVassociated cryptococcal meningitis: a randomised trial. Lancet. 2004;363:1764-7.

69. Robinson PA, Bauer M, Leal MA, Evans SG, Holtom PD, Diamond DA, et al. Early mycological treatment failure in AIDS-associated cryptococcal meningitis. Clin Infect Dis. 1999;28:82-92.

70. Bratton EW, El Husseini N, Chastain CA, Lee MS, Poole C, Stürmer T, et al. Comparison and temporal trends of three groups with cryptococcosis: HIV-infected, solid organ transplant, and HIV-negative/non-transplant. PLoS ONE. 2012. https://doi.org/ 10.1371/annotation/a94bc542-6682-4579-a315-57019cef7e0e.

71. Soria J, Metcalf T, Mori N, Newby RE, Montano SM, Huaroto $\mathrm{L}$, et al. Mortality in hospitalized patients with tuberculous meningitis. BMC Infect Dis. 2019;19(1):9.

72. Kakeya H, Kohno S. Cryptococcosis. Med Mycol J. 2011;52:183-91.

73. Marais S, Thwaites G, Schoeman JF, Török ME, Misra UK, Prasad K, et al. Tuberculous meningitis: a uniform case definition for use in clinical research. Lancet Infect Dis. 2010;10:803-12.

74. Rock RB, Olin M, Baker CA, Molitor TW, Peterson PK. Central nervous system tuberculosis: pathogenesis and clinical aspects. Clin Microbiol Rev. 2008;21:243-61.

75. Lewinsohn DM, Leonard MK, LoBue PA, Cohn DL, Daley CL, Desmond E, et al. Official American Thoracic Society/Infectious Diseases Society of America/centers for disease control and prevention clinical practice guidelines: diagnosis of tuberculosis in adults and children. Clin Infect Dis. 2017;64:111-5.

76. Uniyal R, Garg RK, Malhotra HS, Kumar N, Jain A, Kohli N, et al. Computed tomography thorax abnormalities in immunocompetent patients with tuberculous meningitis: An observational study. J Neurol Sci. 2019;397:11-5.

77. Miyazato A. Mechanism of cryptococcus meningoencephalitis [in Japanese]. Med Mycol J. 2016;57:J27-32.

78. Mukhopadhyay SL, Kumar M, Chickabasaviah YT, Bahubali VKH, Raj PAR, Bharath RD, et al. Cerebellar cryptococcoma due to cryptococcus gattii VGI; a rare and first report from India. JMM Case Reports. 2015. https://doi.org/10.1099/jmmcr.0. 000052.

79. Velamakanni SS, Bahr NC, Musubire AK, Boulware DR, Rhein J, Nabeta HW. Central nervous system cryptococcoma in a Ugandan patient with human immunodeficiency virus. Med Mycol Case Rep. 2014;6:10-3.

80. Ulett KB, Cockburn JW, Jeffree R, Woods ML. Cerebral cryptococcoma mimicking glioblastoma. BMJ Case Rep. 2017. https:// doi.org/10.1136/bcr-2016-218824.
81. Troncoso A, Fumagalli J, Shinzato R, Gulotta H, Toller M, Bava J. CNS cryptococcoma in an HIV-positive patient. J Int Assoc Physicians AIDS Care (Chic). 2002;1:131-3.

82. Dzoyem JP, Kechia FA, Ngaba GP, Lunga PK, Lohoue PJ. Prevalence of cryptococcosis among HIV-infected patients in Yaounde. Cameroon Afr Health Sci. 2012;12:129-33.

83. Jongwutiwes U, Sungkanuparph S, Kiertiburanakul S. Comparison of clinical features and survival between cryptococcosis in human immunodeficiency virus (HIV)-positive and HIV-negative patients. Jpn J Infect Dis. 2008;61:111-5.

84. Miszkiel KA, Hall-Craggs MA, Miller RF, Kendall BE, Wilkinson ID, Paley MN, et al. The spectrum of MRI findings in CNS cryptococcosis in AIDS. Clin Radiol. 1996;51:842-50.

85. Senocak E, Oğuz KK, Ozgen B, Kurne A, Ozkaya G, Unal S, et al. Imaging features of CNS involvement in AIDS. Diagn Interv Radiol. 2010;16:193-200.

86. Sánchez-Portocarrero J, Pérez-Cecilia E. Intracerebral mass lesions in patients with human immunodeficiency virus infection and cryptococcal meningitis. Diagn Microbiol Infect Dis. 1997;29:193-8.

87. Zhang P, Lian L, Wang F. Magnetic resonance imaging features of gelatinous pseudocysts in cryptococcal meningoencephalitis. Acta Neurol Belg. 2019;119:265-7.

88. Hasuo K, Takahashi N, Futoshi M, Yoshiura T, Nishimiya M, Nonoshita T, et al. Radiological diagnosis of tuberculous, fungal, and parasitic infections in the central nervous system. Nichidoku-Iho. 2002;47:285-97.

89. 2021 UNAIDS: United Nations Programme on HIV/AIDS. Tuberculosis and HIV, 2020. https://www.unaids.org/sites/ default/files/media_asset/tb-and-hiv_en.pdf. Accessed on 28 April 2021.

90. Bourgi K, Fiske C, Sterling TR. Tuberculosis meningitis. Curr Infect Dis Rep. 2017;19:39.

91. Bhargava S, Gupta AK, Tandon PN. Tuberculous meningitis-a CT study. Br J Radiol. 1982;55:189-96.

92. Ozateş M, Kemaloglu S, Gürkan F, Ozkan U, Hoşoglu S, Simşek MM. CT of the brain in tuberculous meningitis. a review of 289 patients. Acta Radiol. 2000;41:13-7.

93. Berenguer J, Moreno S, Laguna F, Vicente T, Adrados M, Ortega A, et al. Tuberculous meningitis in patients infected with the human immunodeficiency virus. N Engl J Med. 1992;326:668-72.

94. Wasay M, Khan M, Farooq S, Khowaja ZA, Bawa ZA, Mansoor Ali S, et al. Frequency and impact of cerebral infarctions in patients with tuberculous meningitis. Stroke. 2018;49:2288-93.

95. Müller M, Wandel S, Colebunders R, Attia S, Furrer H, Egger M. Immune reconstitution inflammatory syndrome in patients starting antiretroviral therapy for HIV infection: a systematic review and meta-analysis. Lancet Infect Dis. 2010;10:251-61.

96. Murdoch DM, Venter WD, Feldman C, Van Rie A. Incidence and risk factors for the immune reconstitution inflammatory syndrome in HIV patients in South Africa: a prospective study. AIDS. 2008;22:601-10.

97. Lodi S, del Amo J, Moreno S, Bucher HC, Furrer H, Logan $\mathrm{R}$, et al. Opportunistic infections and AIDS malignancies early after initiating combination antiretroviral therapy in high-income countries. AIDS. 2014;28:2461-73.

98. Post MJ, Thurnher MM, Clifford DB, Nath A, Gonzalez RG, Gupta RK, et al. CNS-immune reconstitution inflammatory syndrome in the setting of HIV infection, part 1: overview and discussion of progressive multifocal leukoencephalopathy-immune reconstitution inflammatory syndrome and cryptococcal-immune reconstitution inflammatory syndrome. AJNR Am J Neuroradiol. 2013;34:1297-307.

99. 2016 Panel on Opportunistic Infections in Adults and Adolescents with HIV. Guidelines for the prevention and treatment of 
opportunistic infections in HIV-infected adults and adolescents; Cryptococcosis. Accessed on 8 Mar 2021.

100. Shelburne SA, Visnegarwala F, Darcourt J, Graviss EA, Giordano TP, White AC Jr, et al. Incidence and risk factors for immune reconstitution inflammatory syndrome during highly active antiretroviral therapy. AIDS. 2005;19:399-406.

101. Post MJ, Thurnher MM, Clifford DB, Nath A, Gonzalez RG, Gupta RK, et al. CNS-immune reconstitution inflammatory syndrome in the setting of HIV infection, part 2: discussion of neuroimmune reconstitution inflammatory syndrome with and without other pathogens. AJNR Am J Neuroradiol. 2013;34:1308-18.

102. Focosi D. Does contrast enhancement predict survival in progressive multifocal leukoencephalopathy? J Infect Dis. 2009;199:1410-1.

103. Berger JR, Levy RM, Flomenhoft D, Dobbs M. Predictive factors for prolonged survival in acquired immunodeficiency syndromeassociated progressive multifocal leukoencephalopathy. Ann Neurol. 1998;44:341-9.

104. Leiderman IZ, Greenberg ML, Adelsberg BR, Siegal FP. A glycoprotein inhibitor of in vitro granulopoiesis associated with AIDS. Blood. 1987;70:1267-72.
105. Grunfeld C, Saag M, Cofrancesco J Jr, Lewis CE, Kronmal $\mathrm{R}$, Heymsfield S, et al. Regional adipose tissue measured by MRI over 5 years in HIV-infected and control participants indicates persistence of HIV-associated lipoatrophy. AIDS. 2010;24:1717-26.

106. García AI, Milinkovic A, Tomás X, Rios J, Pérez I, Vidal-Sicart $\mathrm{S}$, et al. MRI signal changes of the bone marrow in HIV-infected patients with lipodystrophy: correlation with clinical parameters. Skeletal Radiol. 2011;40:1295-301.

107. Hanrahan CJ, Shah LM. MRI of spinal bone marrow: part 2, T1-weighted imaging-based differential diagnosis. AJR Am J Roentgenol. 2011;197:1309-21.

108. Brown TT, McComsey GA. Osteopenia and osteoporosis in patients with HIV: a review of current concepts. Curr Infect Dis Rep. 2006;8:162-70.

109. Tomemori T, Watanabe R, Hiruma K, Mitsuhashi T. A case of facial paralysis in a HIV-infected patient who underwent nerve decompression. Otol Jpn. 2013;23:40-5.

Publisher's Note Springer Nature remains neutral with regard to jurisdictional claims in published maps and institutional affiliations. 